Electronic Supplementary Information

\title{
Biobased divanillin as a precursor for formulating biobased epoxy resin
}

Zhen Fang, ${ }^{* a, b}$ Saeid Nikafshar, ${ }^{c}$ Eric L. Hegg ${ }^{a, b}$, and Mojgan Nejad ${ }^{* c, d}$

${ }^{a}$ Department of Biochemistry \& Molecular Biology, Michigan State University, 603 Wilson

Road, East Lansing, Michigan 48824, United States

${ }^{\mathrm{b}}$ Great Lakes Bioenergy Research Center, Michigan State University, 164 Food Safety and

Toxicology Building, East Lansing, Michigan, 48824, United States

${ }^{\mathrm{c}}$ Department of Forestry, Michigan State University, 480 Wilson Rd, East Lansing, MI 48824

${ }^{\mathrm{d}}$ Chemical Engineering and Materials Science, Michigan State University, 428 S Shaw Ln, East

Lansing, MI 48824

* Mojgan Nejad (nejad@msu.edu)

*Zhen Fang (fangzhe8@msu.edu)

This supporting information contains 4 figures and 2 schemes over 5 pages. 


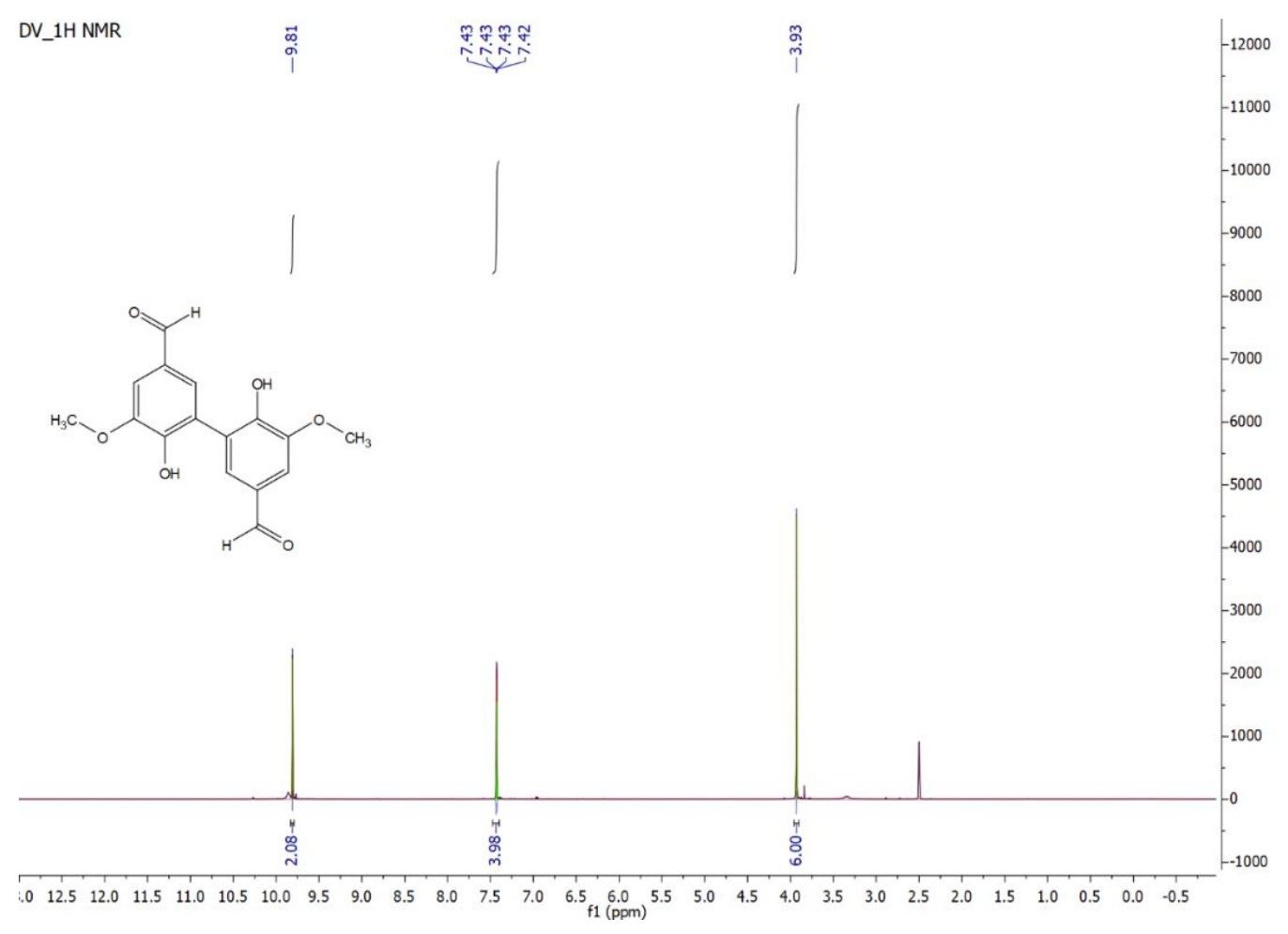

Figure S1. ${ }^{1} \mathrm{H}$ NMR spectrum of divanillin $\left(\mathrm{DMSO}-d_{6}\right)$

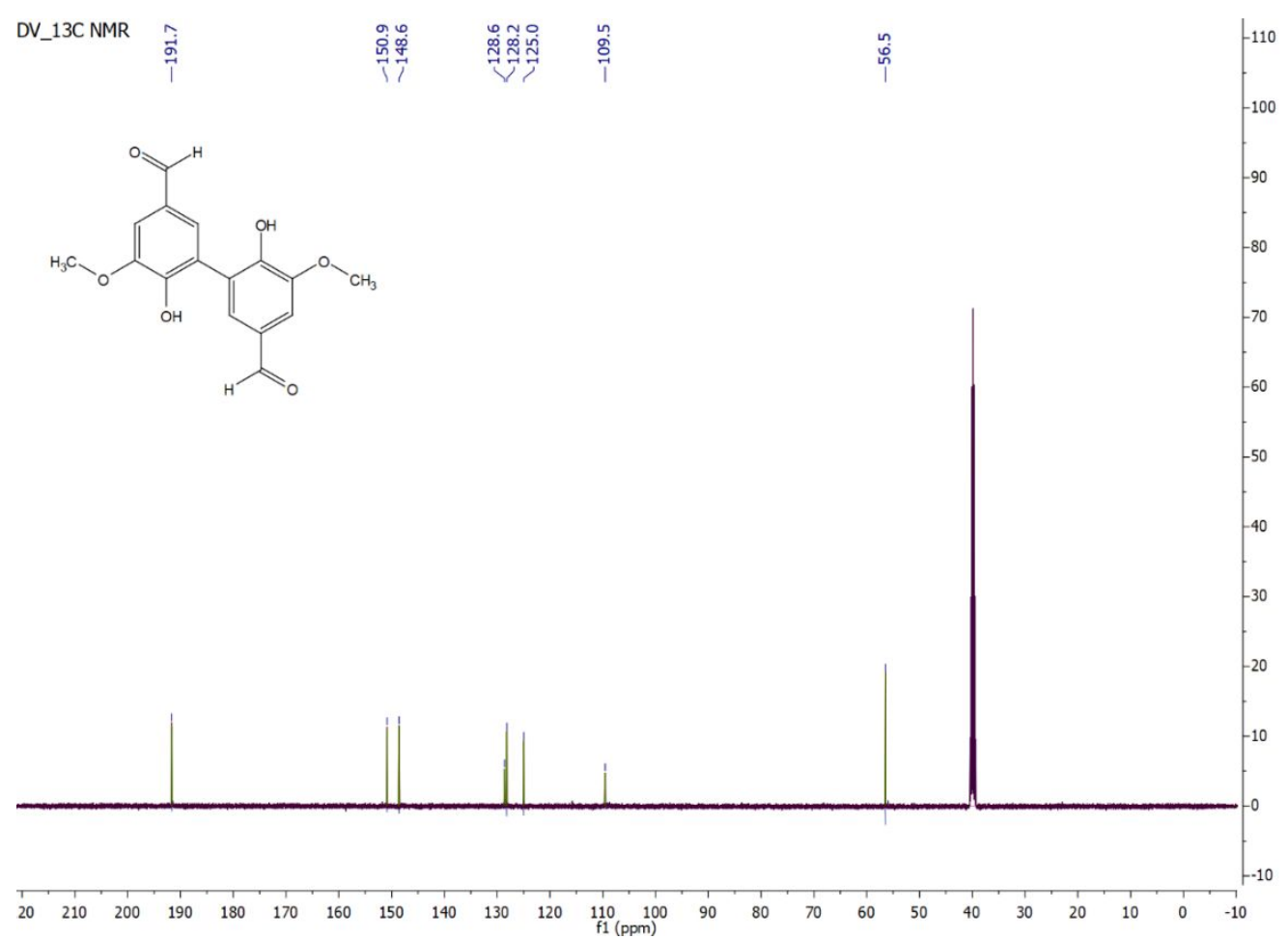

Figure S2. ${ }^{13} \mathrm{C}$ NMR spectrum of divanillin (DMSO- $d_{6}$ ) 


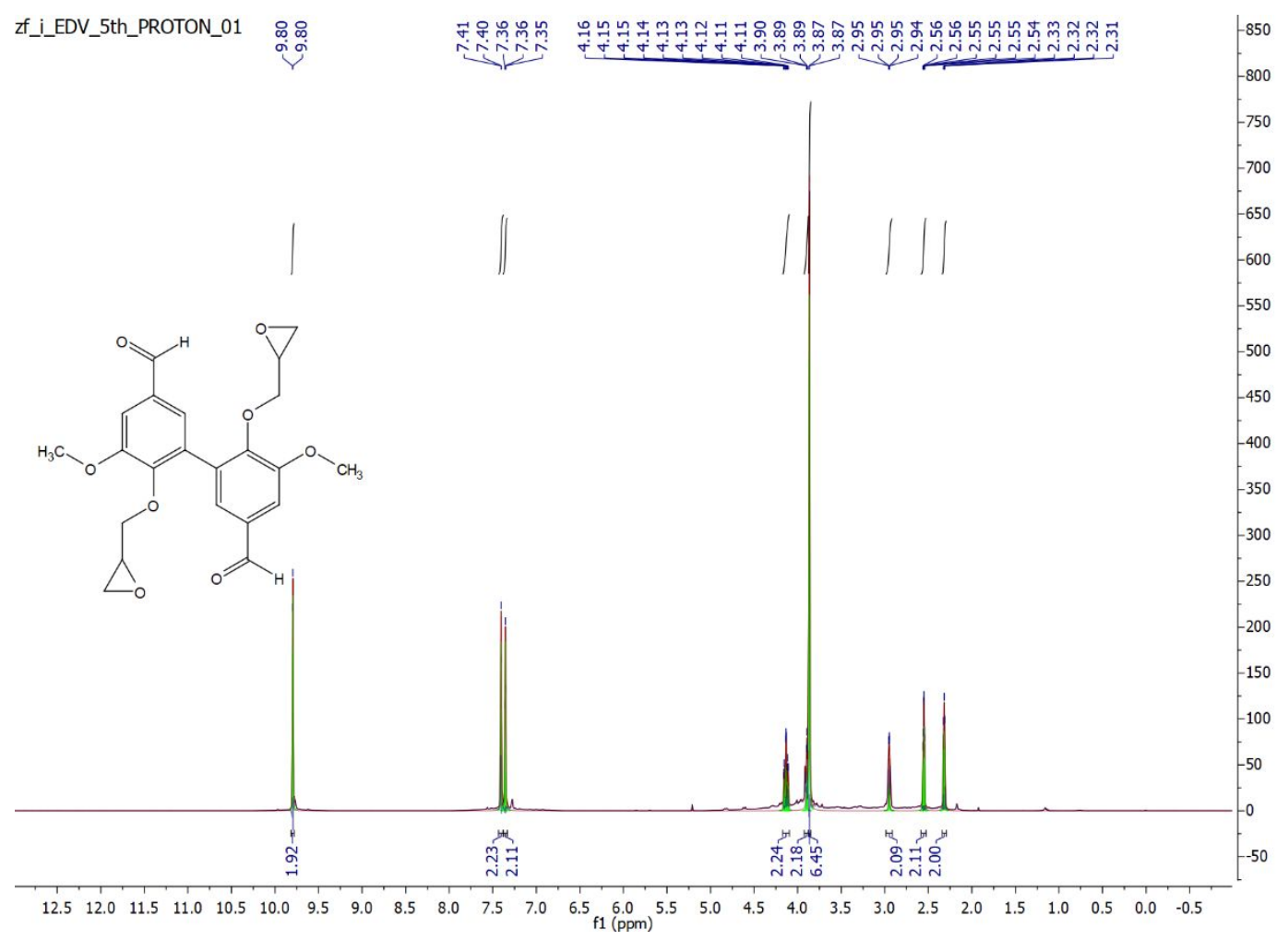

Figure S3. ${ }^{1} \mathrm{H}$ NMR spectrum of epoxidized divanillin $\left(\mathrm{CDCl}_{3}\right)$

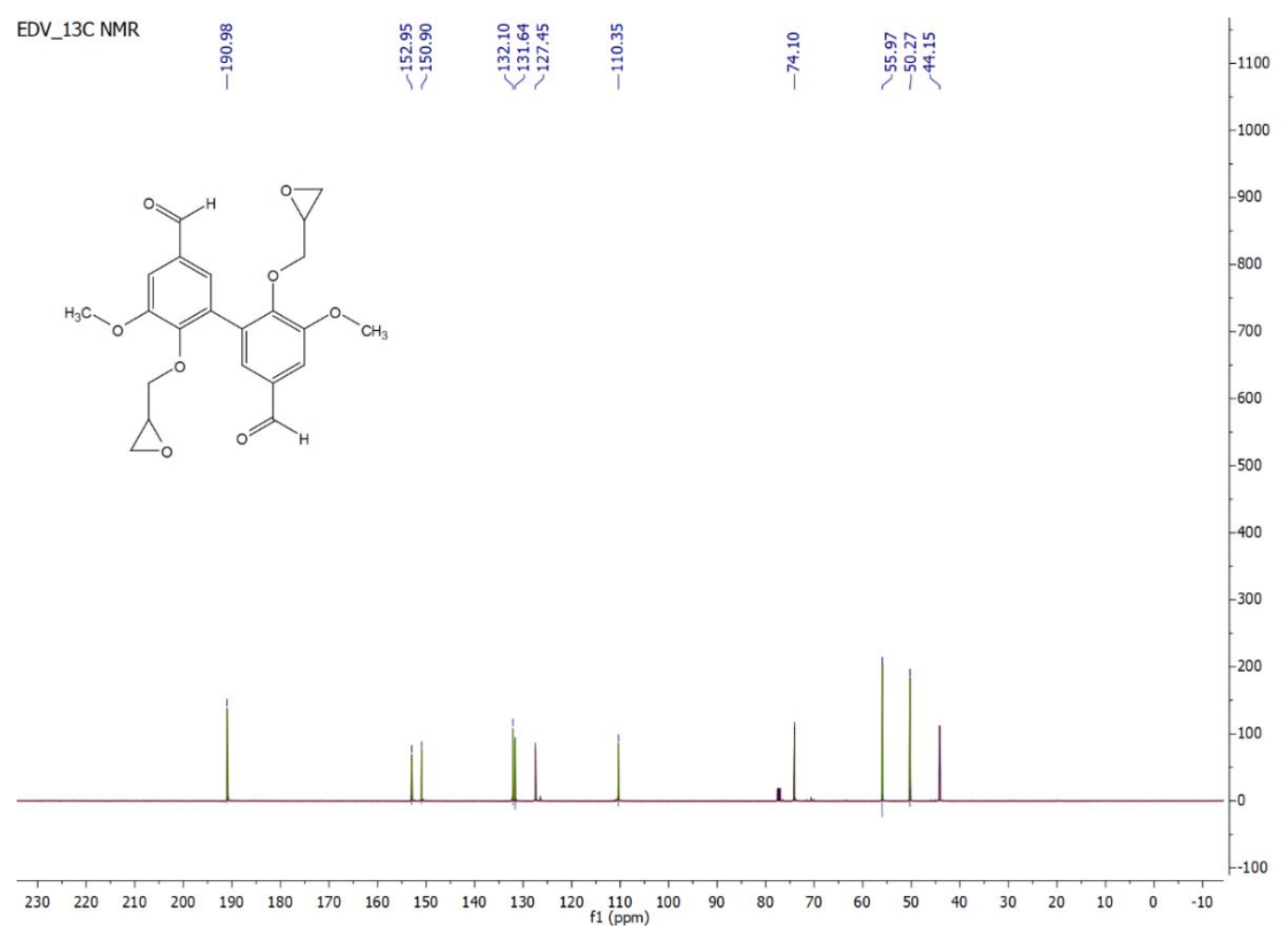

Figure S4. ${ }^{13} \mathrm{C}$ NMR spectrum of epoxidized divanillin $\left(\mathrm{CDCl}_{3}\right)$ 

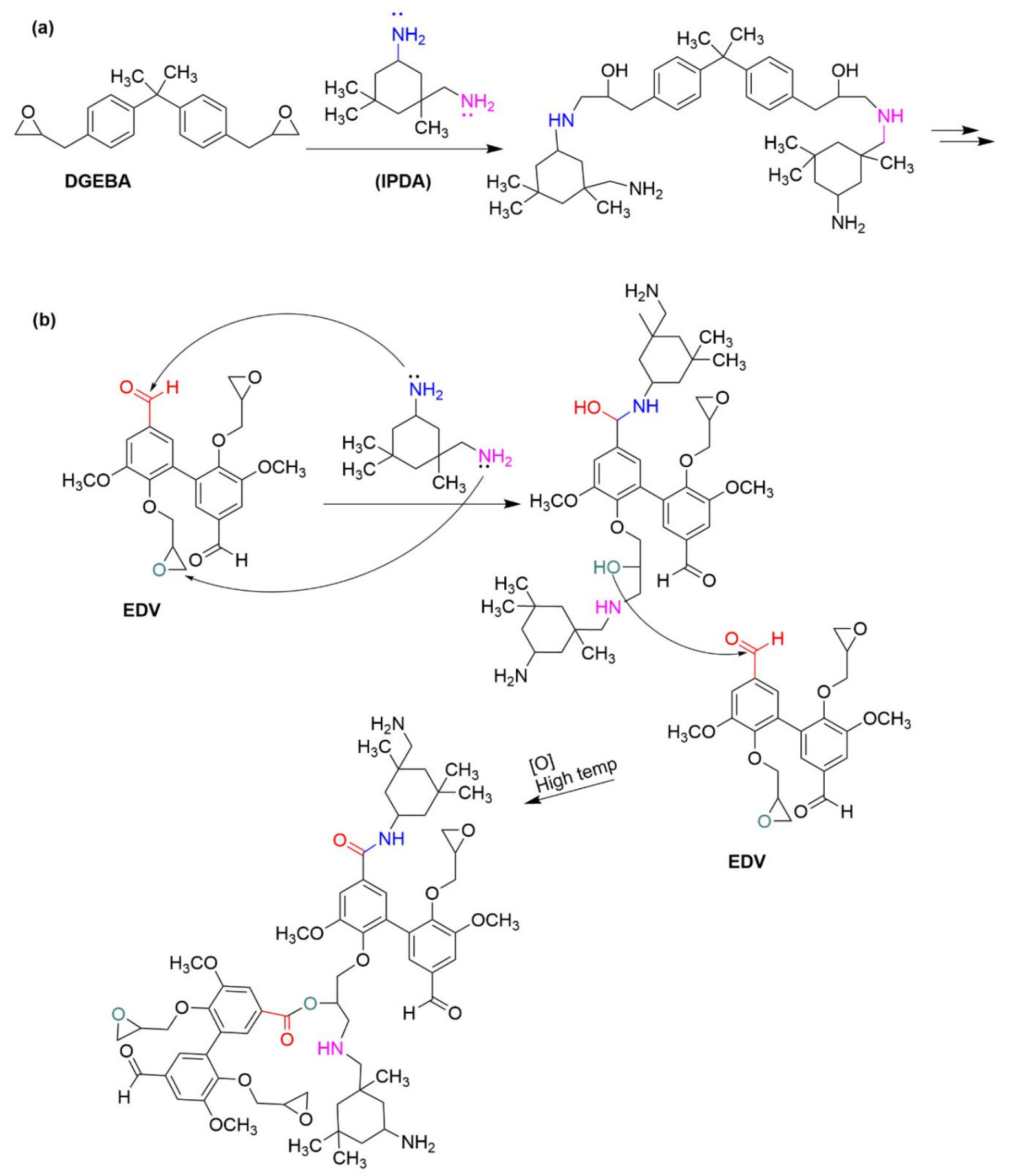

EDV

Scheme S1. Proposed cross-linking reactions between (a) DGEBA/IPDA and (b) EDV/IPDA 


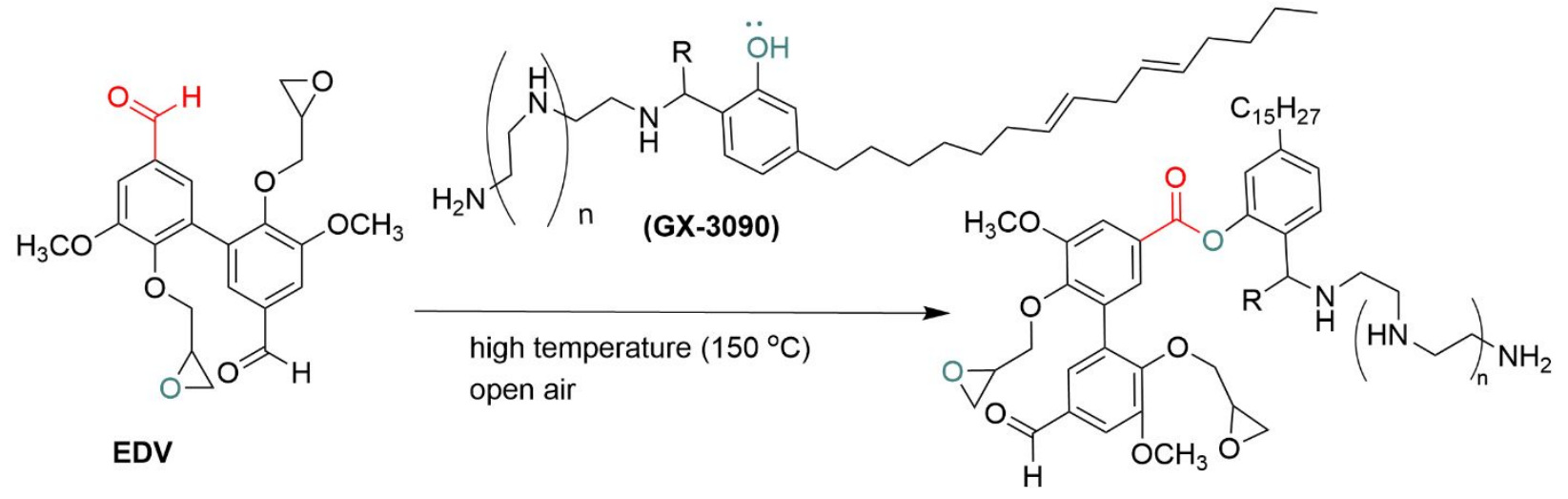

Scheme S2. Additional reaction between the aldehyde group in EDV and phenolic OH in GX3090 